\title{
Exploring Ecosystems from the Inside: How Immersive Multi-user Virtual Environments Can Support Development of Epistemologically Grounded Modeling Practices in Ecosystem Science Instruction
}

\section{Citation}

Kamarainen, Amy M., Shari Metcalf, Tina Grotzer, and Chris Dede. 2014. “Exploring Ecosystems from the Inside: How Immersive Multi-User Virtual Environments Can Support Development of Epistemologically Grounded Modeling Practices in Ecosystem Science Instruction." Journal of Science Education and Technology 24 (2-3) (November 27): 148-167. doi:10.1007/ s10956-014-9531-7.

\section{Published Version}

doi:10.1007/s10956-014-9531-7

\section{Permanent link}

http://nrs.harvard.edu/urn-3:HUL.InstRepos:37231442

\section{Terms of Use}

This article was downloaded from Harvard University's DASH repository, and is made available under the terms and conditions applicable to Open Access Policy Articles, as set forth at http:// nrs.harvard.edu/urn-3:HUL.InstRepos:dash.current.terms-of-use\#OAP

\section{Share Your Story}

The Harvard community has made this article openly available.

Please share how this access benefits you. Submit a story.

\section{Accessibility}


Exploring ecosystems from the inside: How immersive multi-user virtual environments can support development of epistemologically grounded modeling practices in ecosystem science instruction

\author{
Amy M. Kamarainen, Shari Metcalf, Tina Grotzer, and Chris Dede \\ Harvard Graduate School of Education, 13 Appian Way, Cambridge, MA 02139
}

To appear in: Journal of Science Education and Technology

\begin{abstract}
Recent reform efforts and the next generation science standards emphasize the importance of incorporating authentic scientific practices into science instruction. Modeling can be a particularly challenging practice to address because modeling occurs within a socially structured system of representation that is specific to a domain. Further, in the process of modeling, experts interact deeply with domain-specific content knowledge and integrate modeling with other scientific practices in service of a larger investigation. It can be difficult to create learning experiences enabling students to engage in modeling practices that both honor the position of the novice along a spectrum towards more expert understanding and align well with the practices and reasoning used by experts in the domain. In this paper we outline the challenges in teaching modeling practices specific to the domain of ecosystem science, and we present a description of a curriculum built around an immersive virtual environment that offers unique affordances for supporting student engagement in modeling practices. Illustrative examples derived from pilot studies suggest that the tools and context provided within the immersive virtual environment helped support student engagement in modeling practices that are epistemologically grounded in the field of ecosystem science.
\end{abstract}

\title{
Introduction
}

Current efforts toward education reform call for integration of scientific content and practices in classroom instruction, and push for these practices to reflect contemporary qualities of science, summarized by Duschl (2008) as:

1. Emphasizing the role of models and data construction in the scientific practices of theory development,

2. Seeing the scientific community as an essential part of the scientific process, and

3. Seeing the cognitive scientific process as a distributed system that includes instruments, forms of representation, and agreed upon systems for communication and argument.

This paints a picture of science as a creative and iterative process that takes place in a community of practice organized around common goals and operating under jointly held criteria guiding knowledge construction. This sentiment is echoed in a framework put forward by Passmore and colleagues (Passmore et al. 2009; Passmore and Svoboda 2012), which places modeling as a central practice of science across disciplines. Models are a conceptual linchpin due to their descriptive, communicative and associative utility; they can provide a flexible, yet firm representational structure upon which thoughts are built and elaborated, and by which data can be collected and compared. Given the central epistemological role of modeling in many contemporary scientific disciplines, one might argue that modeling should also be a core skill 
cultivated during science learning, and recent work suggests that placing modeling as a core practice supports modes of inquiry that are epistemologically authentic (Windschitl et al. 2008; Passmore et al. 2009).

Engaging students in activities that map closely onto domain-specific practices associated with modeling could help students develop nuanced understanding of the nature of science within that domain, while also reaching domain-specific content understanding goals (Lehrer, Schauble and Lucas 2008; Passmore and Stewart 2002). Modeling is a particularly prevalent tool used in the natural sciences, like ecology and ecosystem science, where scientists are struggling to understand the drivers of and responses to complex socio-ecological problems like climate change. The importance of modeling as a tool for understanding complex natural systems lends a strong argument for using ecosystem science units as a focal point for asking questions related to the design of model-based instructional materials that represent authentic scientific reasoning within the domain (Manz 2012).

Below we describe an ecological multi-user virtual environment curriculum (EcoMUVE), through which inquiry activities in an immersive virtual environment gave rise to conversations that demonstrated nascent modeling practices. We develop the argument that immersion in richly contextualized virtual worlds may place students in an authentic orientation to complex science problems situated in environmental systems, and that technology-enhanced curricula of this kind can support engagement in foundational practices for model development and use in the ecosystem science domain.

What is a "model"?

Reasoning about models is central to the enterprise of science. Models can be thought of as "intellectual sandboxes" in which scientists play with concepts, test ideas, and build the structures of developing theories. The term "model" has been construed broadly across the literatures in science education, for instance, referring to physical, graphical, mathematical, and mental or conceptual representations (Griesemer 1990). Each of these representations are analogous in some respects to the phenomenon under study and can be used to highlight particular features in ways that further understanding (Gilbert 2004).

Science in the classroom has long engaged students with physical models. Physical models solve problems of scale (e.g., teaching about the universe in a classroom within it) (Barab, Hay, Barnett \& Keating 2001; Barnett 2005); inferred entities (e.g., teaching about density, which is inferred from the relationship between mass and volume); and making it possible to manipulate processes and structures to more fully understand their dynamics (e.g., a set of "soda bottle" lungs with a balloon diaphragm) to name a few (Penner, Giles, Lehrer and Schauble 1997, Hmelo, Holton and Kolodner 2000). Physical models play an important role in making concepts more accessible to learners and in inviting them to play with the concepts.

Science in the classroom also engages students with graphical models. Either by hand or computer program, students can represent and manipulate aspects of particular phenomena to see what is revealed. With programs such as the PHet Models (http://phet.colorado.edu/) or the models in Molecular Workbench (http://mw.concord.org/modeler/), students are able to reason about the physical model in relation to the graphical representation and can examine the dynamic relationship between them. 
The term "model" is also used to refer to the conceptual sense or framing that can be used to think about a phenomenon. These conceptual or explanatory models (Clement 2000) embed assumptions about the value of explaining within certain contexts. For instance, Newtonian models make sense within a certain set of constraints, but beyond those constraints (e.g., at quantum scale), their explanatory value falls apart. The constraints and utility of the model are arrived at through investigation, negotiation, and communication. Those that represent phenomena in a useful way are widely adopted and used as heuristic tools within a domain to organize intellectual work.

Each of these types of models-physical, graphical, and conceptual-plays an important role in scientific reasoning and can contribute to powerful learning in the classroom. Current work has also focused on the power of integrating these different kinds of models in classroom instruction (Greca and Moreira 2001), and using technologies to support novel approaches to modeling (Barab et al. 2001). Yet, given the diversity of ways models are used in the classroom, it can be difficult to disentangle the affordances of using models as tools from the value of engaging students in modeling practices. We echo calls in the literature that more work needs to be done to build upon current understanding of the relationship between models, modeling practices, and instructional designs that support modeling practices reflective of the epistemology of a domain (Grosslight et al. 1991; Harrison and Treagust 2000; Gilbert 2004; Lehrer et al. 2008). Below we describe how the design of the curriculum of focus here immerses students in a rich representation of an ecosystem and provides unique opportunities for students to engage in aspects of modeling practice that reflect the epistemologies specific to ecosystem science.

\section{Epistemologically grounded practices in ecosystem modeling}

When scientists engage with models, they bring a host of epistemological assumptions to their thinking and reasoning: some that are general to science (such as the value of exploring alternative explanations) and some that are specific to their discipline (Kelly, Jakeman, Barreteau, Borsuk, Elsawah, Hamilton and Volnov 2013). The Next Generation Science Standards (NGSS), new K-12 science standards in the United States, push towards incorporating epistemological knowledge into how students develop and reason about models and helping students learn epistemologies that support more expert thinking (NGSS Lead States 2013). Below, we explore the epistemic role of modeling in ecosystem science and map the relationship between expert practices and design of model-based instruction.

A survey of ecologists identified the most important reasons for their use of models as 1) to clarify conceptualization of system structure (21\% of respondents), 2) to clarify quantitative relationships between and among system components (20\% of respondents), 3) as a tool for prediction (15\%), and 4) to enhance problem solving (13\%) (Lauenroth, Burke and Berry 2003). Ecologists begin a modeling exercise with a question in mind, and this question is used to help constrain the components and relationships represented in the model. As stated by Canham, Cole and Lauenroth (2003), "Models express the logical consequences of a set of hypotheses." A model, therefore, is a tentative construction that articulates hypothesized ecological relationships, offers insight into potential outcomes, aids further investigation and can be supported or revised based on data and observations of the real system.

As Lehrer, Horvath and Schauble (1994) state "Models are not mental games conducted without reference to the world." Understanding how scientists navigate and toggle between the model, it's implications or "logical conclusions", and evidence from the real world is fundamental. 
Investigators treat models as provisional and maintain a dynamic relationship with the model as they iteratively test its implications in the field, lab or with additional data sets (Lesh and Lehrer 2003). Similar to other scientific fields (e.g., astronomy, geology, evolution), ecosystem scientists study processes that operate at temporal and spatial scales that are difficult to observe or to submit to experimentation. Due to this mismatch in temporal and spatial scales between observation and inference, modeling is a critical intellectual process in ecosystem science, and researchers must use creative strategies to assess the relationship between the model and real-world phenomenon. Researchers in the field of ecosystem science and environmental management are increasingly considering ways that models can be used to integrate multiple forms of evidence to account for both ecological and social dynamics that affect environmental systems (Kelly et al. 2013).

An aspect of modeling that is implicit in the descriptions above, and deserves explicit attention, is the role of models in communication and collaboration. The scientific process is "a distributed system that includes instruments, forms of representation, and agreed upon systems for communication and argument" (Duschl 2008), thus models are a tool within a structured system of representation and carry with them socially constructed conventions that aid communication and collaboration (Goldin 2013). The "clarifying" power of models is realized both by the firstperson creator of the model, and also by those with whom the originator of the model aims to communicate. Models serve as a critical representational tool in the communication of ideas among researchers (Brizuela and Gravel 2013). Particularly in ecosystem science, it is not likely that a single investigator would have appropriate data or background knowledge sufficient to understand the complexities that are represented in ecological models. Therefore, collaboration and communication are core to the scientific process in the field of ecosystem science, and models are a fundamental tool used to support collaboration and communication.

Thus, critical aspects of modeling practice for ecosystem scientists include: 1) considering and constraining the boundaries, structure and relationships to be represented in the model, 2) collecting multiple forms of quantitative data and evidence related to model components and interactions, and 3) comparing expectations outlined in the model to phenomena in the real system through a process of iterative revision, all of which are done in the context of collaboration. Like scientific investigators, students can use modeling as an approach to construct new knowledge, yet the process of doing so will be markedly different for domain novices than for experts. In order to best support student transitions to practices that more closely approximate those that serve the intellectual work of experts, the design of model-based instructional activities should recognize and accommodate distinctions between novice and expert understanding of systems and modeling (Reiser et al. 2001; Lehrer, Schauble and Lucas 2008). Below we describe how an immersive virtual environment encourages students to engage in behaviors that align with aspects of expert modeling practices that are epistemologically authentic and powerful.

\section{Challenges in teaching authentic modeling practices in ecosystem instruction}

Because the time frame for real ecosystems investigations does not match the time available in a classroom setting, ecosystem science instructors have employed a number of creative approaches for demonstrating and investigating various aspects of ecosystem dynamics. A common approach is to use a computer-based simulation that represents abstract components and constrains or expands spatial and temporal scales (Schwartz, Meyer, and Sharma 2007), allowing students to quickly see a summary of the emergent patterns, cascading or rippling 
effects of perturbations, and long-term dynamics of a subset of ecosystem components. A simulation model that demonstrates the dynamics of a predator-prey relationship would be an example of a common simulation used in middle and high school instruction.

While these kinds of simulations are useful in illustrating specific concepts, we argue that they do not provide an appropriate epistemic frame for understanding the process of modeling and the use of models in scientific inquiry. In many cases, such simulation models deliver graphical displays that provide a view of the "logical consequences" of the model without giving students agency in developing the structure or hypotheses that are represented by the model. The actions in which the student can engage (variable manipulation, followed by data interpretation) superficially approximate the actions ecological scientists would take when using a computer model, but remove students from the intellectual work of constructing the model and understanding the problem space. Further, the data generated in these activities tends to be self-referential - the model generates data, students reflect on the relationship between the data and model, and students manipulate variables to generate new data for comparison. In comparison, scientists devote a great deal of time and energy to reconciling anomalous data during the process of theory development (Duschl, 2008). Students often miss opportunities to think about the model and model-generated data in relation to messier, more complex real-world systems. As such, some models used in ecosystem science instruction can come across as separated from the context of scientific investigation and real world application.

These critiques of the representation of models in ecosystem science mirror criticism of laboratory and classroom based inquiry instruction more generally in science education (Chinn and Hmelo-Silver 2000; Windschitl et al. 2008). A literature review in America's Lab Report revealed that there was "almost no direct evidence that typical laboratory experiences that are isolated from the flow of science instruction are particularly valuable for learning specific science content" (Singer, Hilton, Schweingruber 2005, p. 88). The report, however, paints a more optimistic picture of laboratory instruction that is integrated into instructional units, and in which students participate in the "manipulation of ideas instead of simply material and procedures" (Hofstein and Lunetta 2004). Further, an influential study by Chinn and Malhotra (2002) found that many classroom inquiry tasks lead students to an antithetical sense of the epistemology of science. Efforts toward reform acknowledge this conundrum, and argue for the need to integrate authentic practices into the overall curriculum. Practices outlined in the NGSS include planning and carrying out investigations; analyzing and interpreting data; asking questions and defining problems; developing and using models; obtaining, evaluating and communicating information; and constructing explanations and designing solutions (NGSS Lead States 2013). Front matter associated with the NGSS, and current research (Duschl 2008; Lehrer, Schauble and Lucas 2008), make clear that these practices should not be viewed as separate entities, but applied in integrated and authentic ways.

This call for integration fits well with the ways ecosystem scientists creatively invoke combinations and sequences of scientific tools and approaches, including experimentation, observations, rich comparisons, models, long-term studies, and theoretical work to support their arguments and ultimately to construct knowledge (Pace and Groffman 1998). We argue that modeling activities should not constrain opportunities for engagement in appropriate and complementary scientific practices, but should consider the relationship between modeling activities and other scientific practices. 
It is also widely recognized that scientific practices, and perhaps most acutely modeling, are deeply tied to development of content knowledge (Sandoval and Reiser 2004, Manz 2012). Modeling cannot be practiced as an isolated skill, and students must bring to modeling tasks some knowledge of the system, phenomenon, or structure being modeled. This marriage between content knowledge and practices has been a central theme in educational research around science inquiry and practices (Duschl, 2008; Kuhn et al. 2000; Barab et al. 2001, Sandoval and Reiser 2004; Lehrer, Schauble and Lucas 2008; Manz 2012; Windschitl et al. 2008), and questions remain about how best to design instructional tools and environments to support the integration of knowledge and practices.

As outlined above, there are a number of barriers that prevent students from engaging in ecosystem modeling as a nuanced and integrative process. Students frequently lack the background knowledge and reasoning that would help them build arguments about the relationships in the model. Further, students have difficulty organizing and representing data (Lehrer and Schauble 2000; Tairab and Al-Naqbi 2004), which can impede students' ability to confront models with data. EcoMUVE offers scaffolding that may address challenges novices experience when engaging in the practice of modeling, and we explore whether these scaffolds help move students toward more expert approaches. Specifically, the virtual learning experience may address the following challenges:

1.) Experts may construct models based on extensive background information that includes mechanistic understanding of how components of the system should be related. Students often lack appropriate background knowledge necessary to conceive of or construct well-reasoned relationships in a model.

2.) Experts confront their models with relevant, valid and expertly collected data from the real world. Students may not know what data to collect, how to collect it, or how to summarize or interpret these data.

3.) Experts deftly switch among multiple representations: their model, the data, and their experience in the real world, which allows them to iteratively check, or ground-truth, their model and revise their understanding. Students rarely have opportunities to iterate among these types of representation, and have difficulties interpreting the relationship between model and the reality that the model is representing (Coll et al. 2005).

It is important to note a few shining examples in the literature that present extended investigative projects, which incorporate models and modeling practices, and engage students in epistemologically meaningful work that supports development of conceptual understanding and modeling practice (Lehrer, Schauble and Lucas 2008, Manz 2012). Lehrer and others (2008) describe a sixth grade class that conducted a yearlong investigation of pond ecology that included multiple visits to the real pond, developing questions, building model systems in jars in the classroom, weekly science meetings, and an explicit focus on model revision. Similarly. Manz (2012) studied the co-development of conceptual knowledge and modeling practice during a yearlong ecological investigation of plant reproduction that took place in both the outdoor space adjacent to a third-grade classroom and with a variety of model systems in the classroom through which students tested ideas about seed dispersal and reproductive success. These ambitious and powerful approaches align well with authentic scientific practice and generated rich student discussions and learning outcomes. Yet, implementing such in-depth investigations requires levels of commitment, time, and pedagogical content knowledge that are likely difficult to muster in typical classroom contexts. To this point, Lehrer, Schauble and Lucas (2008) speak to the difficulties in creating rich contexts in which authentic inquiry practices can effectively be 
employed in classroom settings. Below we present an immersive virtual environment that provides a rich context that specifically addresses the above outlined challenges associated with modeling practices, and does so in a way that may lower the barriers to implementation.

\section{Why immersion in a virtual world?}

A virtual world enables the enactment of situated learning theory, in which learning is defined as embedded within and inseparable from participating in a system of activity deeply determined by a particular physical and cultural setting (Chaiklin and Lave 1993; Fishman and Dede, in press). The unit of analysis is neither the individual nor the setting, but rather the relationship between the two, as indicated by the student's level of participation (Greeno 1998). From this perspective, learning and cognition are understood both as progress along trajectories of participation in communities of practice and as the ongoing evolution of identity (Wenger, 1998). As a knowledge-centered instructional strategy, immersion positions the learner within a virtual or real-world physical and social context while guiding, scaffolding, and facilitating participatory and metacognitive learning processes such as authentic inquiry, active observation, peer coaching, reciprocal teaching, and legitimate peripheral participation with multiple modes of representation (Palincsar 1998; Squire 2010). Prior research suggests that students tend to gain conceptual understanding when their learning is situated in the context of the problem they are asked to solve and this may be best accomplished by integration of new knowledge derived from a problem-based context with existing knowledge structures (Capon and Kuhn 2004). Immersion provides a space in which we can engage students in a richly contextualized problem space that we hypothesize will facilitate knowledge construction, collaboration and modeling practices.

Immersion provides egocentric and exocentric perspectives on a system (Salzman, Dede, and Loftin 1999), so that students explore the model from within as well as without. Rather than placing students as outside observers of abstracted interactions of a model (as is typically done with simulations), we provide students an opportunity to explore model components and interactions from a position within the system; thus, system dynamics and outcomes are rendered as observable changes in virtual elements that closely approximate analogous realworld structures. At the same time, the virtual world offers a somewhat simplified problem space in which the modeling task is subtly constrained. Students are presented with a manageable number of degrees of freedom; the design aims for a sweet spot between the overwhelming complexity of the real world and oversimplification of a two-species predator-prey simulation. This level of complexity gives rise to competing possible explanations, which can be reconciled through an interactive process of model development, observation, data collection, and argumentation. The positioning of students within a carefully designed, and perceptually analogous virtual landscape, allows learners to take an authentic orientation to the investigation. Their inferences can intuitively emerge from observations, and they can witness relationships and experience their implications as a scenario plays out over time.

Immersion in virtual environments also offers scaffolding by superimposing perceptual overlays on phenomena to support student understanding. The affordances of virtual worlds can allow observation of phenomena that are otherwise impossible to observe without sophisticated scientific tools or prolonged investigation - by zooming in to the microscopic level, traveling to different points in time, and thus seeing effects emerge across various scales of time and distance. Additionally, a virtual environment can support students in their inquiry activities by 
scaffolding the processes of observation and data collection. MUVEs can structure complex tasks and reduce cognitive load, for example, by making it easy to click to retrieve data, by making salient the specific features that are relevant for the investigation, and by organizing data into tables and graphs for analysis. Such conceptual and practical tools can support novice ecosystem science learners as they develop content knowledge and practical skills that ultimately contribute to success in use of modeling practices.

Lesh and Lehrer (2003) describe modeling as a form of literacy - in order to interpret or describe complex systems, learners and investigators must activate and engage with a "variety of interacting media that range from spoken language, to written symbols, to diagrams, to experience-based metaphors, to computer-based simulations" (p. 111). Modeling is a heavily mediated activity, and the different media used to access, communicate and manipulate ideas all emphasize or deemphasize different aspects of the underlying system. One benefit of immersive worlds is that they offer ready toggling among various media resources that can be designed to emphasize or deemphasize different aspects of the system. In practice, Pickering argues that scientific inquiry is "a patchy and fragmented set of processes mobilized around resources." (as cited in Duschl, 2008, p.275). When this process is situated in an immersive virtual world the resources that students need can be available with the click of a mouse, resources can be scaffolded to meet the learners needs, and can be situated in a cohesive and compelling landscape. Situating immersive technologies in the social workspace of the classroom offers additional benefits; students can simultaneously draw on the social and cognitive resources of their peers and teachers. The virtual space can become a shared resource and experience that supports other forms of representation and communication in the classroom, and thus modeling can be placed within a social and collaborative context that anchors its utility as a tool for communication, collaboration, and thinking.

We argue that immersive virtual environments offer affordances that address a number of challenges associated with integrating authentic modeling approaches into science instruction. The immersive environment offers scaffolding and support for perception of important relationships, and for the collection, aggregation and interpretation of data. These scaffolds can support the co-development of content knowledge and process skills that underlie students' ability to engage in authentic modeling practices. The immersive virtual world offers a higher degree of complexity compared to models and simulations typically used in the classroom. We posit that this complexity elicits complex reasoning in that students must bring together and distinguish among multiple forms of evidence in their efforts to identify and support wellreasoned relationships in their models. As students reconcile multiple forms of evidence, the immersive experience places a value on integrating perceptual information with data and other evidence (Dede et al. 1999). We argue that this closely approximates real scientific practice, as students must not only think about whether their argument has internal validity, but must also consider whether their conclusions "make sense" in the context of the complexities of the environment. Finally, the immersive experience and virtual resources become part of a larger suite of learning resources available to students in the socially-mediated learning space within the classroom. We propose that collaborative model building based on shared experiences in a virtual world can lead students to see modeling as a generative and iterative process that emphasizes the social construction of knowledge.

This paper sets forth the idea that immersive simulations are a particularly rich way to introduce students to ecosystem modeling because they 1) provide a rich environment with high fidelity that better approximates the complexity of real environments; 2) provide perceptual overlays 
and scaffolds that address instructional challenges related to temporal scale, collection of evidence, and data analysis; and 3) make it possible to embed epistemological assumptions that are authentic to the domain of inquiry. These last are situated, nuanced, and specific to (in this case) ecosystems science, such as allowing for a dynamic relationship between model, data, and "real" system, as well as integrating practices of modeling, data analysis, and collaboration.

\section{EcoMUVE - an Immersive Representation of an Ecosystem}

Our work builds on prior research that outlines frameworks and design considerations for technological scaffolding for science inquiry and epistemic practices (Quintana et al. 2004; Sandoval and Reiser 2004; Berland and Reiser 2010). EcoMUVE is an ill-structured problem space in which students collaborate to construct meaning about scientific phenomena embedded in the immersive pond or forest environment. Within the immersive virtual environments students have multiple ways of accessing information about the relationships among components of the system, students find opportunities to collect multiple forms of evidence, and the rich relationships among sources of evidence render these open to various interpretations. Thus, the complexity of the immersive world provides a context in which students must justify their interpretation of the relationships as they build and revise a conceptual model of these relationships during an ongoing concept mapping activity.

Some of the learning affordances are rendered specifically through the technologies associated with the multi-user virtual environment (MUVE) format, while other affordances are derived from the placement of this technological tool within its specific pedagogical context. More specifically, the multi-user virtual environment is embedded in a two-week curriculum that also involves classroom discussions, in-person group work, optional worksheets, paper-based concept map construction, and a jigsaw pedagogy. Below we provide an overview of EcoMUVE, and then outline the specific design moves associated with both the technology and the curriculum that address the challenges outlined above.

EcoMUVE was designed to help address specific challenges associated with learning about complex causal systems (Grotzer, Kamarainen, Tutwiler, Metcalf and Dede, 2013; Grotzer, Tutwiler, Dede, Kamarainen and Metcalf, 2011). While observing use of the EcoMUVE curriculum in classrooms we also recognized and documented student activities and conversations that are precursors to or align with authentic modeling practices in the ecosystem sciences. Here, we outline the design affordances that may support engagement in modeling practices, offer descriptive accounts of student conversations from three instances of implementation, and discuss emerging research questions and implications of these observations.

\section{Overview of ECOMUVE}

EcoMUVE includes two ecological multi-user virtual environment modules and associated curriculum for middle school science. EcoMUVE presents students with an ill-structured problem space, and the dynamics, interactions, and data underlying the scenario are based on particular scenarios that could occur in pond and forest ecosystems. Student use a representation of themselves, called an avatar, to navigate around the virtual environment, observe changes that happen over time, and access data collection and graphing tools. Further, the tools and social 
interactions used to understand the phenomenon are designed to be novice translations of domain-relevant practices. This work in which multiple plausible causes are situated in a compelling context requires students to use evidence to support their claims, negotiate meaning within the group, and distinguish between problem-relevant and problem-irrelevant information (Berland and Reiser 2010).

Sandoval and Reiser (2004) argue that rather than focusing efforts on teaching the process of science inquiry, student efforts should be focused on the products that those processes are intended to create and evaluate. To this end, students engage in collaborative construction of a concept map throughout the second half of the EcoMUVE curriculum, which elicits processes and products that are similar to the processes and products of scientific modeling. The concept map served as a shared representation around which students articulate their understanding of the boundaries, components, processes and relationships relevant to the problem or phenomenon identified in the ecological scenario (Goodwin 1994).

Here we describe the two EcoMUVE modules, Pond, and Forest, each of which is associated with a two-week curriculum as outlined below.

\section{Pond Module}

Students begin by using their avatar to visit the virtual pond and its surrounding area, becoming familiar with the species living there. Changes in the ecosystem dynamics of the pond are represented by eight virtual days that students can visit over a period of about two months of the summer, from June 30 to August 15 . As students travel in time, they discover that on July 28th all of the large fish in the pond have died. (Figure 1) They focus on working with their team to develop an evidence-based explanation about why the fish died, via identifying the complex causal relationships between the variables in the pond ecosystem.

The pond module is built on a scenario of eutrophication in which fertilizer runoff induces excessive algae growth followed by nutrient limitation, a crash in the algae population and extensive decomposition by bacteria. These processes combined with warm and windless weather conditions lead to low oxygen conditions that are not sufficient for the survival of bluegill and largemouth bass in the pond. Figure 2 provides a conceptual model that shows all of the causal relationships that contribute to an explanation of the fish kill.

Student can collect water measurements, population data, and weather data over the period of the simulation, and develop their ideas about connections between these variables based on data, observations, and information from learning quests, the field guide, and characters in the world. There are at least two possible explanations that are supported by the available data, and students work together to build a simplified model in the form of a concept map, which represents their evidence-based explanation of the components, relationships and processes that contribute to the fish die-off. The final activity involves students presenting their concept maps and supporting evidence to the class.

\section{Forest Model}

The Forest MUVE is modeled on dynamics that could occur in northern hardwood forests dominated by hemlock, maple, and beech trees. In EcoMUVE, there are two islands, Dover and Willis Islands, which are part of a forested state park. The forest and associated ecological 
communities are quite similar on the two islands; however, only Willis Island has a population of wolves. In contrast, there have never been wolves on Dover Island. Students observe and collect data on both islands to investigate how and why the patterns of change over time are different between the two islands.

On Dover, the deer population increases to its carrying capacity; and the flowers, shrubs, and saplings that deer like to eat are disappearing from the island. The bird species that use the shrubs as habitats are likewise decreasing, through birds who nest in trees still thrive. Meanwhile, on Willis Island, students observe predator-prey cycles of the deer and wolf populations, as well as an impact of predation on small mammals. Students also learn about the life cycle of deer ticks and monitor Lyme disease risk, learning that the ticks that cause Lyme disease are more closely related to the small mammal populations than to the deer. Figure 3 shows a representation of the causal relationships on which the Forest module is based.

Students travel through time to visit the islands every five years between 1975 and 2020. As in the pond module, students observe plants and animals, shrink to view microscopic organisms, collect data, and graph changes in the populations of different species. Student teams collaborate to discover patterns in their observations and to understand the relationships among the organisms, with the goal of understanding why fewer tourists have been visiting the park on Dover Island in the recent virtual past.

\section{Description of Case Studies}

Descriptive accounts are drawn from multiple studies of both Pond and Forest EcoMUVE in classrooms in order to explore how the curriculum and immersive environment may support students' engagement in modeling practices. Specifically, these exploratory data were assembled in response to our guiding question, "Does participating in the EcoMUVE curriculum elicit student engagement in modeling practices that reflect authentic practices in the domain of ecosystems science?" These pilot studies conducted during 2011-2013, included the classes of three 7th grade teachers in similar, moderately affluent, northeastern school districts. Two of the teachers used the Pond module and one used the Forest module, during a two-week period. Each teacher taught four $7^{\text {th }}$ grade science classes, for a total of approximately 250 students, ages 12-13. Students worked in teams of four to five students.

We collected video and audio recordings of a subset of student groups during their concept mapping activities. In two classes (one Pond and one Forest), a researcher was present as groups worked together to construct their concept maps, a process which involved both group work on paper and individual work with EcoMUVE on the computers. Those students video or audio recorded were selected on an impromptu basis by the researcher based on groups that were actively discussing their concept maps at the time of the recording. In one class using EcoMUVE Pond, four student teams were selected by the teacher to be audiotaped for the last four days of the Pond curriculum, during which groups shared their ideas, analyzed data, and constructed their concept maps. The exploratory analysis of video and audio recordings focused on transcribing student conversations and identifying instances in which student conversations revealed engagement in authentic modeling practices. These accounts are meant to provide illustrative examples that describe the kinds of modeling practices that were elicited during the activity. The concept mapping activity was a focal point because we consider the concept map a novice representation of a model, and initial observations indicated that student discussions 
revealed nuanced ways the immersive environment had prepared them to engage in epistemologically grounded model-based reasoning during the concept mapping activities.

The descriptions presented below are anchored in expert modeling practices outlined in the sections above; we discuss how the design of the EcoMUVE technologies and curriculum are positioned to support student moves toward more expert modeling practices. Finally we conclude each section with descriptive examples from three classroom cases, to illustrate how student engagement in modeling practices looked during EcoMUVE.

\section{Supporting Development of Modeling Practices}

A rich environment for learning content and understanding the structure and relationships of the system being modeled

Experts rely on domain-specific content knowledge in order to determine the structure and relationships that should be included and represented within a model. This may involve defining the temporal, spatial and conceptual boundaries of the system in question - what time and space scales should be considered? What components of the system should be included in the model? In working with middle school students, we cannot assume that students have previously developed the content knowledge that would support the definition of important components and relationships to be included during the modeling process, so engaging in the modeling process also requires development of content knowledge related to the target system to be modeled. The EcoMUVE curriculum provides integrated access to multiple learning resources that support situated development of content knowledge relevant to the modeling task, these include perceptual cues, information in multiple virtual media (field guides, virtual characters, atom tracker tool), and data in the form of tables and graphs. These learning resources are omnipresent in the world and accessible on multiple virtual days through time travel. Below we further describe the virtual learning resources, and we offer illustrative excerpts that demonstrate how students used these resources during discussion and construction of their concept maps.

There are multiple learning resources available to students while they are immersed in the virtual world. Students gather information by interacting with non-player characters (NPCs); for example, on the first virtual day, students find Manny, the landscaper at the housing development, who says that he is putting down extra fertilizer to get ready for an open house (Figure 4). On other days, students meet a jogger who mentions that the pond "smells like sewage," and a public utility worker who said she checked the sewage pipes and found no evidence of a leak. Throughout the virtual experience, students can use a camera tool to take photos of organisms and learn about them in the online field guide (Figure 5).

As students explore the world, they learn it has unique properties compared to real ecosystems. They discover that their avatar can walk under the water to observe the fish and aquatic plants in the pond, and can use a submarine tool that shrinks them to microscopic size to consider organisms that they cannot normally see, including the algae and bacteria that play a critical role in the pond ecosystem. An atom tracker tool also gives students a situated view of ecological processes at the atomic level, such as photosnythesis. The Forest Module provides a special "zoom tool" that highlights the presence and location of forest animals that would otherwise pass unnoticed. These views of the world use the power of the technology to support students as they develop contextualized knowledge of important ecosystem components, concepts and 
processes, many of which are not observable or apparent to students in a typical classroom context.

Moving through the Pond environment allows observation of spatially distributed phenomena, as students, via their virtual avatars, explore the pond and surrounding watershed area, including a nearby golf course and a housing development. Salient features of the environment are represented as tacit sensory clues. It is an uphill walk from the pond to the housing development, and students can walk down along a drainage ditch and through the pipe where runoff flows into the pond. As other examples, the pond becomes noticeably greenish during the algae bloom and students can witness changes in the size and types of trees that are growing in the virtual forest. Students measure pond turbidity, but also experience it directly as visible clarity or cloudiness of the water when they go into the pond on different days. Students collect population data, but may also notice visual cues of the number of algae or bacteria visible in the microscopic submarine in the Pond and notice significant changes in the forest animal and plant populations between the two forested islands (Figures 7 and 8).

To illustrate how these affordances of the virtual environment supported development of domain-specific content knowledge, we share dialog from a pair of students who refer to using perceptual cues, time travel, virtual water measurement tools, and integrated graphical displays to gain a contextualized sense of what "turbidity" means.

\section{School3_Group4}

S2 it's how cloudy the water is...

S1: the pond looks like you cant really see very well. You can't really see anything

$\mathrm{S} 1$ : that makes sense...cause the chlorophyll makes it really green

S2: And the turbidity is high

S1: more green and less clear

S2: the turbidity is low on $25^{\text {th }}$

S2: (points to something on the graph) So, this is where the turbidity is low, so you can see the water. You can see everything in the water

S2: Well, so I was just saying that the turbidity is really high on the day that you can't see anything in the water. And its really low on the day that you can see a lot on the water, so turbidity is measuring how cloudy the water is.

Notably, these students recognize that chlorophyll and turbidity are related and connected to how green the water is. Such perceptual cues embedded throughout the virtual landscape help students to develop content knowledge that is deeply situated in a context that is analogous to real world ecosystems.

The example below also shows reliance on multiple forms of information in order to gain the content knowledge needed to construct the concept map. Specifically, these students toggle between the virtual forest field guide, and graphs of their data in order to develop their ideas.

\section{School1_Group1}

S3: What do the wolves eat? Do they just eat deer, or do they eat small mammals too?

S4: We should check that out.

[S3 opens the entry for the timber wolf in the online field guide, while S4 watches. S3 reads out loud.] 
S3: when a single wolf hunts alone it hunts and eats smaller prey such as rabbits and other small mammals

[S3 switches to graph, they select deer, small mammals, and wolves to display over time]

S3: So small mammals and white tailed deer are affected by the wolves.

S4: [points] Yeah, when this starts going down this goes back up, when this starts rising this goes back down.

Easy-to-access field guide information and change-over-time graphs for forest populations help these students to gain content knowledge about the diet and behavior of timber wolves, which they use to draw relationships among the organisms represented in their concept maps.

In the example below, students discuss changes over time in the bacteria concentration in the pond and explore two different ideas about the role of bacteria in the fish death. To discuss and resolve the conceptual link between bacteria and the fish death, these students rely on data and graphs, information from the field guide, and information about ecosystem processes (bacterial respiration) derived from tracking carbon atoms in the ecosystem on different dates.

\section{School2_Group1}

S7: So on the $28^{\text {th }}$, when you saw the fish die, there was an increased number of bacteria. Because on the $30^{\text {th }}$, when all the things were normal, there was 5000 but on the $28^{\text {th }}$ there was 33,000 so...

S5: Wow!

S7: ...so maybe it has to do with the filth?

S5: No maybe it's just from the fish dying and all the bacteria in their bodies are being released.

S6: Some bacteria are good so I mean...

S5: Yeah, not all bacteria are bad so that's not necessarily...

S7: Oh you guys! When I was tracking carbon... On the $10^{\text {th }}$, there was a lot of bacteria, and on then $16^{\text {th }}$ they took in oxygen. So I think that's also why some of the fish died because if there is an increase number of bacteria on the $28^{\text {th }}$ they're taking in even more oxygen which is also making the fish die. And also the minnows eat a lot and so that was a lot of oxygen and they're giving out a lot of carbon dioxide and minnows tend to eat small things like bacteria and algae...

Having access to multiple sources of information allows these students to engage in a process of triangulation among information sources in order to negotiate the meaning of "bacteria" within the system in question. As such, some students appeared to attend to discordant data and observations raised by their peers. While doing so, we observed students expanding and refining their understanding of the components and relationships that are important in ecological systems.

These excerpts demonstrate a common pattern we observed where students accessed and integrated multiple forms of information while discussing ecosystems concepts, many of which were previously unfamiliar. The immediacy and accessibility of the correspondence between visual cues in the virtual environment, information sources (like the field guide and atom tracker), and the data in the graphs seems to help students to make sense of concepts like turbidity, food web relationships, and the role of biotic and abiotic factors that might have been implicated in the problem at hand. Thus, virtual learning resources embedded throughout the 
virtual landscape seemed to help students develop relevant content knowledge while embedded in a context that visually and conceptually related to real world ecosystems. Developing such contextualized content knowledge is a foundational step in supporting students' ability to create conceptual models that represent meaningful ecological relationships. This suggests that virtual immersive worlds may support co-development of content knowledge and process skills that could support further development of modeling practices.

\section{Scaffolding data collection and interpretation}

While experts can plan and carry out a rigorous sampling procedure that would generate reliable data against which the "logical consequences" of the model can be tested, novices tend to have little knowledge of suitable data collection procedures and little sense of the statistical implications of various sampling approaches. It is important to confront models with data from the system, but we argue that this process may be approximated using data that are constrained for the user. The virtual world offers affordances that can support learners using data in service of the modeling process without prerequisite knowledge about procedural aspects of data collection, aggregation and representation.

In the design of tools to support data collection and graphing, we attempted to balance tradeoffs between presenting tools that represent the semantics of the discipline, automating non-salient tasks, and rendering data easily interpretable in the context of the concept mapping activity (Quintana et al. 2004). Over a period of 3 to 5 class periods, student teams collect virtual data over the periods of the scenario. The data collection procedure is simplified in that students only need to click on a measurement tool, then click on the organism or property they are interested in measuring. The value is displayed and automatically saved to the student's data table. The data collection process is complicated by the fact that students must figure out where to look for particular organisms and must know the distinction between the types of measurements that can be collected with any given tool. These understandings are supported through the development of student roles and associated learning quests.

The excerpt below shows an exchange between two students as they become familiar with the simplified process of data collection available within the virtual world.

\section{School2_Group3}

S8: How do you do the heron population?

S9: it's so easy, the herons are at the same place every time.

S8: So where are they?

S9: They're on the hill. You do the large mouth bass. I'll do the herons.

S8: Where's the large mouth bass?

S8: They're in the water.

S9: So you look for one? And then you click them?

S8: Yeah.

While the above excerpt demonstrates how the data collection process is significantly simplified compared to real data collection (e.g., the students assume they can find the herons "at the same place every time"), it also reveals how easy it is for students to reach a state of data collection proficiency within the virtual context. Simplified data collection procedures allow students to turn their attention to data interpretation, and students can easily shift to viewing tables and graphs of their data. Given that inferring causal connections by interpreting 
relationships that unfold over time is a primary challenge in ecosystem science, the graphing tools focus on changes in variables over time. The graphs allow display of up to five variables at a time, each scaled to its range over the simulation to support viewing of qualitative patterns over time (Figure 6). Students can easily toggle back and forth between tabular and graphical representations of the data, and students can share what they've collected with one another to assemble a more extensive data set. In the Forest Module, the graphs for Dover and Willis Island are shown on the same display to aid comparison of the patterns between the two islands.

To complement the temporal focus of the graphing tools, students use the affordances of the technology to travel forward and backward in virtual time. Initial time spent in the virtual environment is quite open ended, and students travel freely through time. This means that some students notice and point out changes occurring in the virtual environment, and in the Pond Module the guiding question "what killed the fish" rises from the discovery of dead fish on the shoreline late in the virtual summer. Changes in the Forest Module are more subtle, yet the presence of two islands sets an expectation that comparison will be important. The immersive world provides a context in which students can combine measurement with time travel to get a situated understanding of how changes are manifest both in the world and in the abstracted representation of their data.

The conversation below shows a number of ways in which a group used temporal data to support their decision about whether to include $\mathrm{pH}$ as a component in their concept map.

\section{School2_Group2:}

S11: Why would the fertilizer kill the fish?

S10: Maybe it has extra $\mathrm{pH}$ or chemicals in it.

S12: The fertilizer sinks into the soil ... if the fertilizer goes far enough underground, it could soak into the water and have something to do with the $\mathrm{pH}$ level.

S11: ... but throughout the whole time the $\mathrm{pH}$ was normal. It has nothing to do with $\mathrm{pH}$.

S12: What was the $\mathrm{pH}$ on July $28^{\text {th }}$.

S11: On the $28^{\text {th }}$ ? Well that doesn't matter because the fish were already dead.

S12: Yeah, but its still important.

$\mathrm{S} 11: \ldots$ the $\mathrm{pH}$ level was 7.6

S12: Yeah, so that's normal. So we now know, the $\mathrm{pH}$ level isn't in this. The $\mathrm{pH}$ has nothing to do with this.

S10: So the $\mathrm{pH}$ didn't kill the fish!

S11 attempts to limit the temporal boundaries of the question to include only the time period prior to the fish kill, while $\mathrm{S} 12$ argues that additional data for $\mathrm{pH}$ is still relevant as a means to establish a sense of what's "normal" for the system. The example demonstrates that, through a process of assembling data over an extended time frame, students were able to refute the hypothesized relationship between $\mathrm{pH}$ and fertilizer, and therefore decided not to include $\mathrm{pH}$ as a component in their model.

The facilitated comparison of data over time and space seemed to help students engage in conversations about what conditions and data should be regarded as "normal" and what might be anomalous. The process of learning to define and identify aberrant data or conditions was important in isolating which components and processes should be considered as part of the problem space, and which could be omitted. As students accumulated and synthesized these 
various forms of information, they evaluated the validity of evidence they'd collected as they used the information in service of the connections they drew in their concept maps.

Throughout the process of concept map construction, we observed students using content knowledge and data to negotiate criteria for which components, processes and relationships should be included in their model, including consideration of the validity of different forms of evidence. For example, we observed that the alignment (or misalignment) between data, observation, and testimony from non-player characters in the virtual provided opportunities for students to distinguish between confirmatory or dis-confirmatory evidence. The example below provides an example where students are seeking and integrating multiple forms of evidence during their discussion, but have to reconcile whether testimonial evidence given by an NPC is confirmed by further observation or data, in doing so they refer to temporal patterns in the graphs, seeing trash in the water, and talking to NPC characters in the world.

\section{School2_Group2:}

S12: There is obviously something wrong with the water. During the period of June $30^{\text {th }}$ and July $28^{\text {th }}$ something's going on with the water.

S10: I think there was something about VHS (viral hemorrhagic septicemia)?

S13: I don't think it's natural.

S10: It's not natural.

S12: Maybe it could have something do with the pollution.

S13: The pollution!

S10: There was suspicion about a sewage leak but a person went down and checked it out and it turns out there was no leak.

S12: Yeah but we don't know. We don't have any evidence that says...

S10: There was a woman that went down and actually checked for a leak and there was none.

S12: Do you think that if people went down and threw trash in the water that maybe... I didn't see trash in the water but...

S13: They would have made that a point [referring to the trash as something they should consider]

S12: [to S10] Since you're the private investigator - did you talk to anyone about pollution? What did the say?

S10: Yeah! There was one person that thought there was a sewage leak - pretty sure it was Manny - because the water smelled really bad but then there was another woman who had a job there, in the sewage business, and it turns out there was no leak.

S12: So obviously you can't trust the person who thought there was a sewage leak - the person who works there obviously knows best.

The multiple forms of both confirmatory and dis-confirmatory evidence that are available in the virtual world helped to elicit student conversations about the need for evidence and validity of different data sources.

In other instances, the act of seeking coherence between the model and data leads students to either reconsider their assumptions or notice additional factors that could have a role in the scenario. In the example below, a student has a working hypothesis that the bacteria caused the fish to go down, and tries using a food web mechanism to explain the relationship. As she seeks confirmatory evidence based on patterns in the graphs, she identifies a negative correlation between bacteria and the algae and blue-green algae (rather than fish). Additional 
prompting from the researcher helps the student reconsider her assumptions, and realize that if bacteria were eating the fish, there would be a different pattern in the data than the one she is observing.

\section{School3_Group1}

$\mathrm{R}$ : [sees S1 looking at different graphs, asks what she is looking for]

S14: Well, I'm looking for what the bacteria could have eaten here [talking about the graph she is looking at].

$\mathrm{R}$ : [prompts $\mathrm{S} 1$ to talk more about what exactly she is looking for]

S14: Things that bacteria could eat. If that makes sense? It might have been algae.

$\mathrm{R}$ : [asks why $\mathrm{S} 1$ thinks this]

S14: Because the algae goes down when the bacteria starts going up. So I think it might have been algae. Same with the blue green algae. I think that could be it. I don't think it's a kind of fish, and it's probably not a heron. So it's probably the blue green algae that caused the bacteria to go up and the fish to go down.

$\mathrm{R}$ : The question is still, how did the bacteria cause the fish to go down

S14: Cause it started to eat the fish.

$\mathrm{R}$ : [asks $\mathrm{S} 1$ if bacteria eats fish]

S14: Well it eats it when they're dead. Wait... oh.

This student appears to go through a process of revising her ideas based on comparison between patterns in the data and her working knowledge of the ecological relationships in the system.

Below we present another example where a student uses patterns in the graphs to support a dynamic process of reasoning. This student actively adds data to a graphical representation in order to test a working hypothesis on the fly; the easy-to-use graphical display appears to support a collaborative process of sense making during the concept mapping activity.

\section{School2_Group4}

S15: (talking to his team): This is the graph [displaying DO, the large mouth bass and bluegill fish populations]. I think there's not enough dissolved oxygen. And so these [fish] went down as well... And also, if you look at it, let me see if we put in wind speed. [Student uses popup menu to add "windspeed" as a fourth variable in the graph] Look at this! Wait, okay. So look it. These died right here, the two fish, between July 25 and July 28. See that? Okay. So that happened because the dissolved oxygen went down. The reason why the dissolved oxygen went down is because the wind speed came down. The way that the dissolved oxygen gets in the water is cause the wind speed pushes it in the water. And when the wind speed goes down, the dissolved oxygen goes down, so the fish die.

Another common pattern we observed was that students sometimes collected "all" the data (i.e. to fill in the entire data table available in EcoMUVE) first, and then looked for patterns and relationships. For example,

\section{School2_Group1}

[In response to teacher question, S5 says]

S5: Oh, we're pretty much completely filled in. So we've got it pretty much all. Except for those two because there is no information available. 
S5: [talking to himself] Air temperature? Pretty similar. Wind speed? Wow!

S5: The wind speed was at its second highest on the same day all the fish died. That's interesting.

S5: [talking to himself and making a mental note of all the data he is checking] Cloud cover? No, that was at like an all time low. So that's not it. Phosphates? Nitrates?

Turbidity? PH - tested. Chlorophyll - tested. Wind speed. Bacteria population. Blue-gill population. Green algae population - Oh wow! The algae population was at an all time low.... Heron population. Large mouth bass population.

Approaches that included collecting "all" the data and then focusing on anomalous data (spikes or dips in the data graphs) seemed to appeal to a number of students. Such an approach does not align with an authentic approach to collecting and analyzing data from real ecosystem because it is impossible to collect all the data from a real ecosystem, so researchers must be strategic and thoughtful about which data to collect. Further, whether high and low readings indicate an important change in the system depends on the relative change in the factor and potential mechanisms that link changes in one factor to another. Some students' discussions indicated that they were considering the data along with mechanistic understanding of the relationships among ecological components, but other students seemed to rely on whether a change in one factor was followed by a change in another as the primary basis for supporting a relationship between the factors.

In many conversations, we observed students engage in a process of reconciling multiple sources of information, and there were cases in which students reconciled confirmatory and disconfirmatory data to support and constrain the processes and relationships chosen to be represented in their concept maps. The easy-to-use data collection and aggregation tools seemed to limit student frustration with data collection and allow them to focus on the process of interpretation and negotiation needed to achieve coherence among multiple forms of evidence and the model represented in their concept maps.

Toggling among multiple representations - integrating practices of model revision, data analysis and collaboration

Models are a tool within a larger collaborative communication system that includes various forms of representation that have different degrees of abstraction, and these representations can be called upon during the process of scientific argumentation and sense making. Experts are able to deftly switch among different forms of representation, use different forms appropriately during communication, and build arguments that acknowledge and account for the limitations and values of different representations and abstractions. Further, experts collaborate with colleagues who have complementary areas of expertise in order to construct their models and appropriately define the relationships and contingencies represented in the model.

EcoMUVE provides scaffolding that supports rapid interplay between conceptual understanding, data and the model. A rapid shifting among representations is supported by the integration of learning resources within the virtual environment (as discussed in the section above), but is also supported by specific aspects of the curriculum In EcoMUVE, students activities are scaffolded using a jigsaw pedagogy, which allows individuals to develop a particular area of expertise; students work in teams of three to five students during the two week curriculum. Within a team, 
each student has a different role and becomes more expert in this role by collecting data and engaging in learning quests, which help them develop background knowledge pertinent to their role. For example, the Water Chemist role learns about dissolved oxygen, whereas the Microscopic Specialist learns about bacteria. A role worksheet is used to help guide students by suggesting aspects of the virtual world that an expert of that role would pay attention to.

Throughout the curriculum, students gain particular content knowledge as they work to become more expert in their role. As students share data with one another and construct their concept maps, they realize additional data they want to collect, think of observations that they should go back and check, and they return to the virtual world and travel through time to confirm or refute a tentative claim, or see how their interpretation compares with a classmate's. While these behaviors do not directly align with the practices and constraints of real science, providing students with an ability to rapidly transition between data, their concept map and their virtual experience does align with the process scientists use, either through mental exercises or through a cycle of modeling, data collection, experimentation and analysis that occurs over a much longer time frame. We are interested in whether a sequence of events that may on the surface seem fantastical (time travel and slipping in and out of a virtual world) can scaffold important cognitive moves that aid interpretation and transition among different forms of representation.

The exchange below shows students who are quickly shifting among media as they construct a representation of their understanding of the relationships in the model. The students toggle between factual information presented in the online field guide, digital graphs of numeric population data, and a paper-and-pencil version of their concept map.

\section{School1_Group2}

Student S15 has the field guide open to the deer page, and is reading from it.

Student S16 has the graph view open showing different populations over time. Between the two students is some paper on which the students are drawing a pencil draft of a concept map. Looking at both screens, and they have this conversation:

S15: So look, the deer eats parts of trees including leaves, twigs, seedlings... We know that the ovenbirds they build their nests.. from,... those are probably twigs, leaves.

S16: Yeah, yeah, yeah.

So that means the deer probably likes eating the nests. So that means the nests are affecting the bird population because they don't have enough habitat, S16: Yeah, they can't live. And then the saplings decrease.

S16: ...The small mammals have the bacteria on them

S15: They have the ticks on them, and then they carry it.

S16: Oh, the the ticks go there [points at concept map]

S15: Yeah, we can move that over there

S16: This is just a rough draft.

S15: Lyme disease must be affecting some of the other animals too.

S16: Yeah, some bigger animals.

S15: We should probably ask our Lyme Disease specialist. [opens graph showing population data] Because we didn't see an immediate correlation between the whitetailed deer and the ticks. So I think.

S16: Maybe indirect.

S15: Yeah, indirect relationship. 
Toggling among resources, treating the model as provisional, and seeking collaboration are all aspects of modeling practice that are epistemologically authentic, and not witnessed often enough in traditional classrooms (Windschitl et al. 2008).

A second example, below, shows how students engaging with this activity held the view that the concept maps (here referred to as "charts") they were constructing would represent different theories about why the fish in the pond died. The students initially had two different working hypotheses about what killed the fish. Through a process of negotiation and revision, this group of students eventually converged on a single model that they felt best represented the factors relevant to the fish kill.

\section{School2_Group2}

S13: Lets work on the chart now. We have two charts, so should each chart have a different theory to it?

S10: Yeah, I'll do the fertilizer one.

S10: [putting things on the concept map] The fertilizer runs into the lake...

S11: I agree with S4, I think it's not just the fertilizer, there has to be something else.

Because I don't think that many fish would die from JUST fertilizer.

S10: Yeah, and its not like all the fertilizer in the field could have ran down to the lake

S11: Maybe since there were two kinds of fish that died, maybe one fish...

S10: But that theory doesn't make any sense because then the minnows would have died.

S13: But minnows eat microscopic things

S10: But they still could have breathed it in through their gills because it would have been dissolved in the water. Well... maybe they are just too small?

S13: Yeah, cause they don't take in as much oxygen or energy as the larger fish.

S11: Maybe they breathed it in but it didn't really killed them, it just made them sick I bet a lot of the surviving fish had just a tiny amount in their bodies, like not enough to kill them but maybe enough to make them sick

S12: You know what I noticed on the beach that day? There were no minnows there. And when I stepped in the water, I think I maybe saw like one.

S10: Yeah, I think I saw like one but that was it. Hmmm. I wish we could, like, perform an autopsy on the fish so we could find out what killed them.

S13: Cause like, if it was the fertilizer, why didn't it kill the minnows?

S10: Yeah, like why didn't it kill all of them?

In addition to these students demonstrating collaborative construction of their concept map, the students bring up additional inferential methods that they would like to use (performing an autopsy), and tacitly acknowledge the limitations of the virtual world for pursuing truly openended inquiry.

In many cases we observed collaborative conversations during which the majority of students in the group were involved in the conversation around the concept maps. It may be that the jigsaw pedagogy was particularly useful in supporting collaboration and involvement, as each student had developed different areas of expertise, and the students developed an understanding of the scope of one another's expertise. This knowledge of roles and reliance on one another for important parts of the puzzle is demonstrated in exchanges between S12 and S10 (School2_Group2) above, and between S15 and S16 in clip School1_Group2 above. In addition to collecting in situ references as students worked together in groups, we captured students' 
reflections on group work during informal interviews with a researcher. In response to a prompt about "how easy or hard it was to figure out how things fit together", one example response indicates the students' views of the value of working together with teammates who had different areas of expertise.

\section{School3_Group2}

S17: "it is difficult to figure out how things fit together... You can see each clue, but you can't put them together without thinking and collaborating... we realized that there must be something connecting - like how this went up and those went up and then S18 thought of the reason why would go up. If we had been separate, I don't think we would've figured that out."

\section{Discussion}

We argue that EcoMUVE addresses many goals prevalent in the NGSS and recent theoretical work around modeling and epistemology related to using disciplinary concepts in domainrelevant contexts and settings (Sandoval and Reiser 2004; Lehrer, Schauble and Lucas 2008; Manz 2012, Windschitl et al. 2008). Using immersion to position students within an ill-structured problem space seemed to help them engage in collaborative sense making that encouraged use of evidence in support of claims. The behaviors of students included collecting data, distinguishing between problem-relevant and problem-irrelevant information, and collaboratively reasoning about the claims represented in their concept maps by combining prior knowledge and repeated visits to the virtual environment to revise their understanding. Thus, immersion in the virtual world, supporting design and curricular features, and the concept mapping task elicited behaviors that are closely aligned with the epistemic work of experts in the field of ecosystem science.

Modeling has been a subsidiary part of larger discussion around inquiry learning, where there exists a conceptual divide between two ways of framing inquiry in instruction: 1.) a focus on inquiry as a means to understand the nature of science, and 2.) use of inquiry as a mode for students to take an active role in sense-making while learning core science content (Sandoval 2014). Placing modeling as central in the process of science inquiry may help to break down barriers between these world views because models are useful as representations for communication and cognitive thought, and the modeling process is core to authentic epistemological work in many scientific domains (Duschl 2008; Windschitl et al.2008). Explicitly incorporating models and modeling into science instruction and the inquiry process may support students toward a better understanding of the nature of contemporary science, and toward developing conceptual schema that hold organizational and representational utility for communication, argumentation, and sense-making (Passmore and Svoboda 2012; Windschitl et al. 2008). EcoMUVE provides a context in which students have opportunities to better understand the scientific process through being immersed in a virtual environment and participating in collaborative model construction and revision.

A critical aspect of modeling practice is the interpretation of the logical consequences of the relationships in the model and relating these to data from the real world. Student work on concept maps approximated this process, and revealed instances in which students connected claims to both data and perceptual clues in the immersive environment. Other research highlights the challenges students often have in connecting claims and evidence (Berland and Reiser 2010; Berland and McNeill 2009). We found that in some cases students were able to 
appropriate new sources of information as evidence and connect these to claims in their concept maps (e.g. S7 in School2_Group1), but in other cases, students held more strongly to their initial ideas about the kinds of relationships that should be presented in the concept map, and were not able to reconcile their prior understanding with new sources of information. For example, students who maintained their claim that the fish died due to a lack of food despite reviewing the field guide information that held contradictory information about their dominant source of food. These findings suggest areas for future research on how students discriminate among and assign value to data sources and information, and how students reconcile prior knowledge with contradictory observations based on virtual experiences.

We found evidence that students were engaging in nuanced approaches to data interpretation while working within the immersive environment. Students developed ideas about what ranges and observations should be considered "normal" in the context of their data and observations. Further, students used perceptual clues from the virtual environment to guide data interpretation. Students spoke of the relationship between turbidity readings and the "murkiness" of the pond, while other students noticed changes in fish behavior that they were able to relate to dissolved oxygen concentrations shown in their graphs. This suggests that through the scaffolds provided and the easy transitions between data and the real environment, students were able to build a more epistemologically rich interpretation of the evidence they had collected (Sandoval and Reiser 2004). While we observed rich data interpretation and reasoning processes exemplified above, we also noticed that a number of rich exchanges and instances where students demonstrated deeper exploration of the data were supported by teacher, researcher prompting. A follow-on research project could be designed to assess the relative importance of adult assistance in the eliciting of more complex data-based reasoning behaviors.

Prior research has suggested that model revision is an important part of modeling practice (Hmelo, Holton and Kolodner 2000), and yet others speak to the challenges in supporting student in revision of models and claims (Berland and Reiser 2010). We argue that the EcoMUVE immersive environment and curriculum encouraged students to consider and engage in revision practices by providing easy transitions among representations. We saw examples of students quickly toggling between multiple sources of evidence to examine the correspondence among the sources and then updating the information to be presented in their concept maps. Lehrer, Horvath and Schauble (1994) write of models that they "guide the seeking of evidence". Based on our findings it appeared that the concept mapping activity inspired student to bolster the scope and validity of their evidence, and the immersive world provided ready access to resources that supported evidence collection.

The immersive virtual environment in EcoMUVE supports a scaffolded introduction to engagement with models. Scientists build models because they seek to better understand the relationships, and mechanisms contributing to a phenomenon in question (Stratford 1997). The EcoMUVE curriculum places students in a richly contextualized immersive virtual environment that supports them bringing the same intentionality to the modeling process. The virtual world, scaffolded by jigsaw pedagogy and technological tools, invites students to explore multiple possible explanations, discriminate among varied source of evidence, and quickly transition among complementary representations. These affordances of the immersive technology and associated curriculum helped engage students in nuanced modeling behaviors that align with expert practices, and addressed some of the challenges inherent in teaching modeling practices in the ecosystems science classroom. 


\section{References}

Barnett, M., Yamagata-Lynch, L., Keating, T., Barab, S. A., \& Hay, K. E. (2005). Using Virtual Reality Computer Models to Support Student Understanding of Astronomical Concepts. Journal of Computers in Mathematics and Science Teaching, 24(4), 812-856.

Berland, L.K. and K.L. McNeill. (2009). Using a learning progression to inform scientific argumentation in talk and writing. Learning Progression in Science

Berland, L.K. and B.J. Reiser. (2010). Classroom communities' adaptations of the practice of scientific argumentation. Science Education, 95 (2), 191-216

Barab, S. A., Hay, K. E., Barnett, M., \& Keating, T. (2000). Virtual Solar System Project: Building Understanding through Model Building, Journal of Research in Science Teaching, $37(7), 719-756$.

Canham, C. D. W., Cole, J., \& Lauenroth, W. K. (Eds.). (2003). Models in ecosystem science. Princeton University Press.

Capon, N., \& Kuhn, D. (2004). What's so good about problem-based learning?. Cognition and Instruction, 22(1), 61-79.

Chaiklin, S. and Lave. (Eds.)(1993) Understanding Practice: Perspectives on Activity and Context.

Chinn, C., and Malhotra, B (2002). Epistemologically authentic inquiry in schools: A theoretical framework for evaluating inquiry tasks. Science Education, 86(2), 175-218. doi:10.1002/sce.10001

Clement, J. (2000). Model based learning as a key research area for science education. International Journal of Science Education, 22(9), 1041-1053. doi:10.1080/095006900416901

Coll, R. K., France, B., and Taylor, I. (2005). The role of models/and analogies in science education: implications from research. International Journal of Science Education, 27(2), 183-198. doi:10.1080/0950069042000276712

Dede, C. (1999). The Multiple-Media Difference. Technos, 8(1), 16-18.

Duschl, R. (2008). Science Education in Three-Part Harmony: Balancing Conceptual, Epistemic, and Social Learning Goals. Review of Research in Education, 32(1), 268-291. doi:10.3102/0091732X07309371 
Fishman, B., Dede, C., and Means, B. Teaching and technology: New tools for new times. Handbook of research on teaching, 5th edition. Washington, DC: American Educational Research Association.

Gilbert, J. K. (2004). Models and Modelling: Routes to More Authentic Science Education. International Journal of Science and Mathematics Education, 2(2), 115-130. doi:10.1007/s10763-004-3186-4

Goldin, G. A. (2013). "Show Me what You Know": Exploring Student Representations Across STEM Disciplines. B. M. Brizuela, and B. E. Gravel (Eds.). Teachers College Press.

Greca, I. M., and Moreira, M. A. (2002). Mental, physical, and mathematical models in the teaching and learning of physics. Science Education, 86(1), 106-121. doi:10.1002/sce.10013

Greeno, J. G. (1998). The situativity of knowing, learning, and research. American Psychologist, 53(1), 5-26. doi:10.1037//0003-066X.53.1.5

Griesemer, J. R. (1990, January). Material models in biology. In PSA: Proceedings of the Biennial meeting of the Philosophy of Science Association (pp. 79-93). Philosophy of Science Association.

Grosslight, L., Unger, C., Jay, E., and Smith, C. L. (1991). Understanding models and their use in science: Conceptions of middle and high school students and experts. Journal of Research in Science Teaching, 28(9), 799-822. doi:10.1002/tea.3660280907

Grotzer, T. A., Kamarainen, A. M., Tutwiler, M. S., Metcalf, S., and Dede, C. (2013). Learning to Reason about Ecosystems Dynamics over Time: The Challenges of an Event-Based Causal Focus. BioScience, 63(4), 288-296.

Grotzer, T.A., Tutwiler, M.S., Dede, C. Kamarainen, A., and Metcalf, S. (2011, April). Helping students learn more expert framing of complex causal dynamics in ecosystems using EcoMUVE. Presented at the National Association of Research in Science Teaching (NARST) Conference, Orlando, FL. (April 4, 2011).

Harrison, A. G., and Treagust, D. F. (2010). International Journal of A typology of school science models,, 37-41. doi:10.1080/095006900416884

Hmelo, C. E., Holton, D. L., and Kolodner, J. L. (2000). Designing to Learn About Complex Systems, The Journal of the Learning Sciences, 9(3), 247-298.

Hofstein, A., \& Lunetta, V. N. (2004). The laboratory in science education: Foundations for the twenty-first century. Science education, 88(1), 28-54.

Kelly, R. A., Jakeman, A. J., Barreteau, O., Borsuk, M. E., Elsawah, S., Hamilton, S. H., and Voinov, A. A. (2013). Environmental Modelling \& Software Selecting among five common modelling approaches for integrated environmental assessment and management. Environmental Modelling and Software, 47, 159-181. doi:10.1016/j.envsoft.2013.05.005 
Kuhn, D., and Pearsall, S. (2000). Developmental Origins of Scientific Thinking. Journal of Cognition and Development, 1(1), 113-129. doi:10.1207/S15327647JCD0101N_11

Lauenroth, W. K., Burke, I. C., and Berry, J. K. (2003). The status of dynamic quantitative modeling in ecology. Models in Ecosystem Science. Princeton University Press, Princeton, 32-48.

Lehrer, R., Schauble, L., and Lucas, D. (2008). Supporting development of the epistemology of inquiry. Cognitive Development, 23(4), 512-529. doi:10.1016/j.cogdev.2008.09.001

Lehrer, R., Horvath, J., and Schauble, L. (1994). Developing Model-Based Reasoning. Interactive Learning Environments, 4(3), 218-232. doi:10.1080/1049482940040304

Lehrer, R., \& Schauble, L. (2000). Developing Model-Based Reasoning in Mathematics and Science, Journal of Applied Developmental Psychology, 21(1), 39-48.

Lesh, R., \& Lehrer, R. (2003). Models and Modeling Perspectives on the Development of Students and Teachers. Mathematical Thinking and Learning, 5(2-3), 109-129. doi:10.1080/10986065.2003.9679996

Manz, E. V. E. (2012). Understanding the Codevelopment of Modeling Practice and Ecological. Science Education, 96(6), 1071-1105. doi:10.1002/sce.21030

NGSS Lead States. 2013. Next Generation Science Standards: For States, By States. Washington, DC: The National Academies Press.

Pace, M. L., and Groffman, P. M. (1998). Successes, Limitations, and Frontiers in Ecosystem Science: Reflections on the Seventh Cary Conference OR. Science, 137-142.

Palincsar, A. S. (1998). Keeping the Metaphor of Scaffolding Fresh--A Response to C. Addison Stone's "The Metaphor of Scaffolding Its Utility for the Field of Learning Disabilities". Journal of learning disabilities, 31(4), 370-373.

Passmore, C., and Stewart, J. (2002). A modeling approach to teaching evolutionary biology in high schools. Journal of Research in Science Teaching, 39(3), 185-204. doi:10.1002/tea.10020

Passmore, C. M., and Svoboda, J. (2012). Exploring Opportunities for Argumentation in Modeling Classrooms. International Journal of Science Education, 34(10), 1535-1554. doi:10.1080/09500693.2011.577842

Passmore, C., Stewart, J., and Cartier, J. (2009). Model-Based Inquiry and School Science: Creating Connections. School Science and Mathematics, 109(7), 394-402. doi:10.1111/j.1949-8594.2009.tb17870.x

Penner, D. E., Giles, N. D., Lehrer, R., and Schauble, L. (1997). Building functional models: Designing an elbow. Journal of Research in Science Teaching, 34(2), 125-143. doi:10.1002/(SICI)1098-2736(199702)34:2<125::AID-TEA3>3.0.CO;2-V 
Quintana, C., Reiser, B. J., Davis, E. A., Krajcik, J., Fretz, E., Duncan, R. G., and Soloway, E. (2004). A scaffolding design framework for software to support science inquiry. Journal of the Learning Sciences, 13(3), 337-386.

Reiser, B., Tabak, I., Sandoval, W. A., Smith, B. K., Steinmuller, F., and Leone, A. J. (2001). BGulLE: Strategic and conceptual scaffolds for scientific inquiry in biology classrooms. In S. M. Carver \& D. Klahr (Eds.), Cognition and Instruction:Twenty-five years of progress. Lawrence Erlbaum Associates.

Salzman, M., Dede, C., and Loftin, B. (1999). Virtual reality's frames of reference: A visualization technique for mastering abstract information spaces. Proceedings of $\mathrm{CHI}$ ' 99 , pp. 489-495.

Sandoval, W. (2014). Science Education's Need for a Theory of Epistemological Development. Science Education, 98(3), 383-387. doi:10.1002/sce.21107

Sandoval, W. A., and Reiser, B. J. (2004). Explanation-driven inquiry: Integrating conceptual and epistemic scaffolds for scientific inquiry. Science Education, 88(3), 345-372.

Schwarz, C. V, Meyer, J., and Sharma, A. (2007). Technology, Pedagogy, and Epistemology: Opportunities and Challenges of Using Computer Modeling and Simulation Tools in Elementary Science Methods, 243-269. doi:10.1007/s10972-007-9039-6

Schweingruber, H. A., Hilton, M. L., and Singer, S. R. (Eds.). (2005). America's Lab Report:: Investigations in High School Science. National Academies Press.

Squire, K. (2010). From information to experience: Place-based augmented reality games as a model for learning in a globally networked society. Teachers College Record, 112(10), 2565-2602

Stratford, S. J. (1997). A Review of Computer-Based Model Research in Precollege Science Classrooms, 16, 3-23.

Tairab, H. H., and Khalaf Al-Naqbi, A. K. (2004). How do secondary school science students interpret and construct scientific graphs? Journal of Biological Education, 38(3), 127-132. doi:10.1080/00219266.2004.9655920

Windschitl, M., Thompson, J., \& Braaten, M. (2008). Beyond the scientific method: Model-based inquiry as a new paradigm of preference for school science investigations. Science education, 92(5), 941-967.

Wenger, E. (1998). Communities of practice: Learning, meaning, and identity. Cambridge university press. 


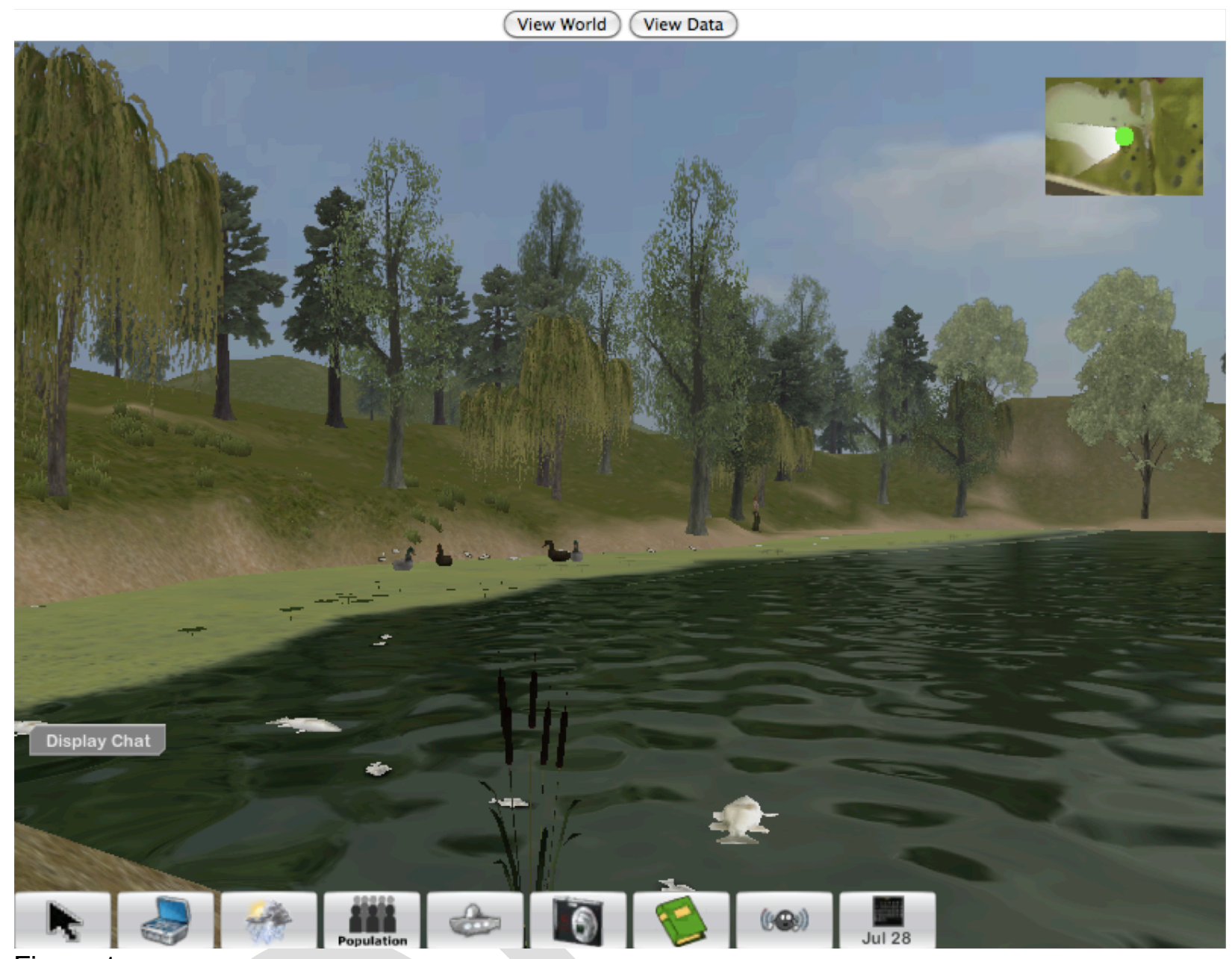

Figure 1.

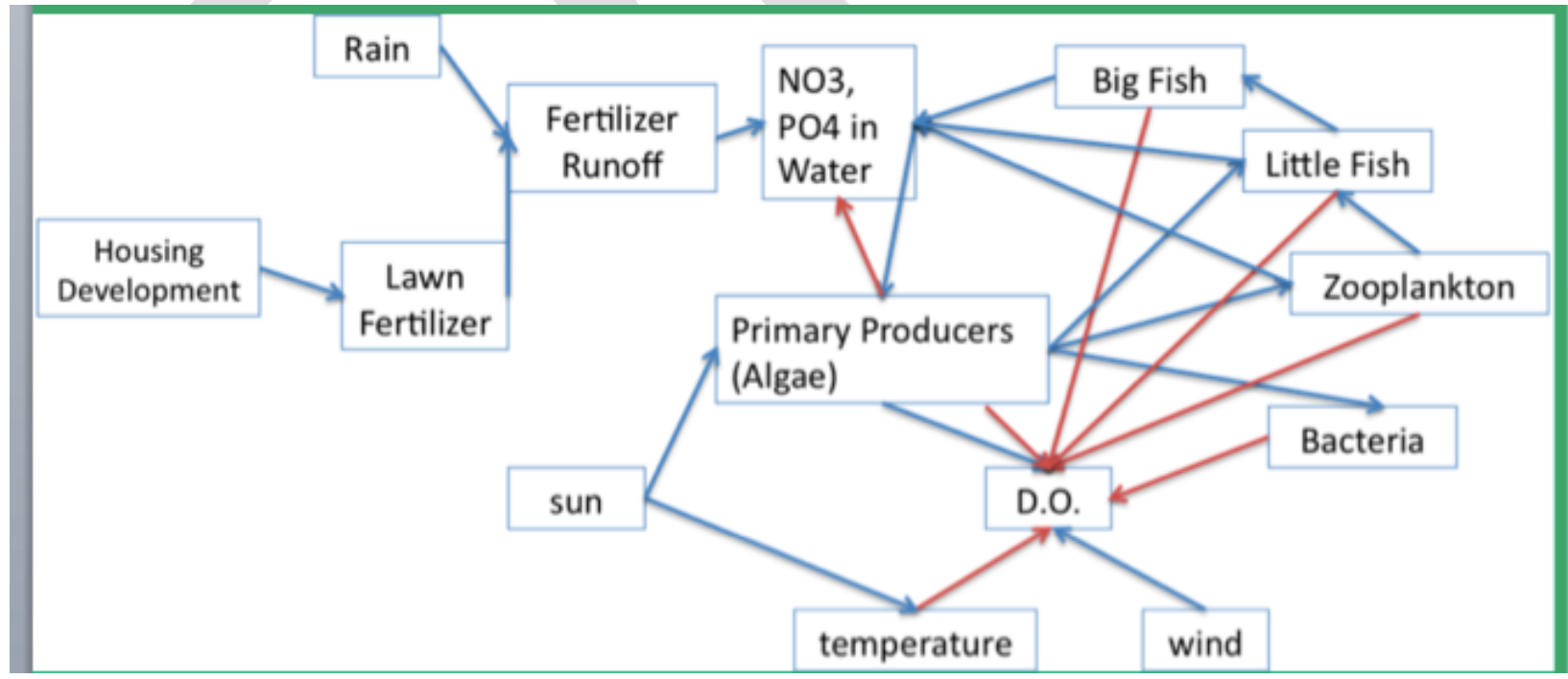

Figure 2. 


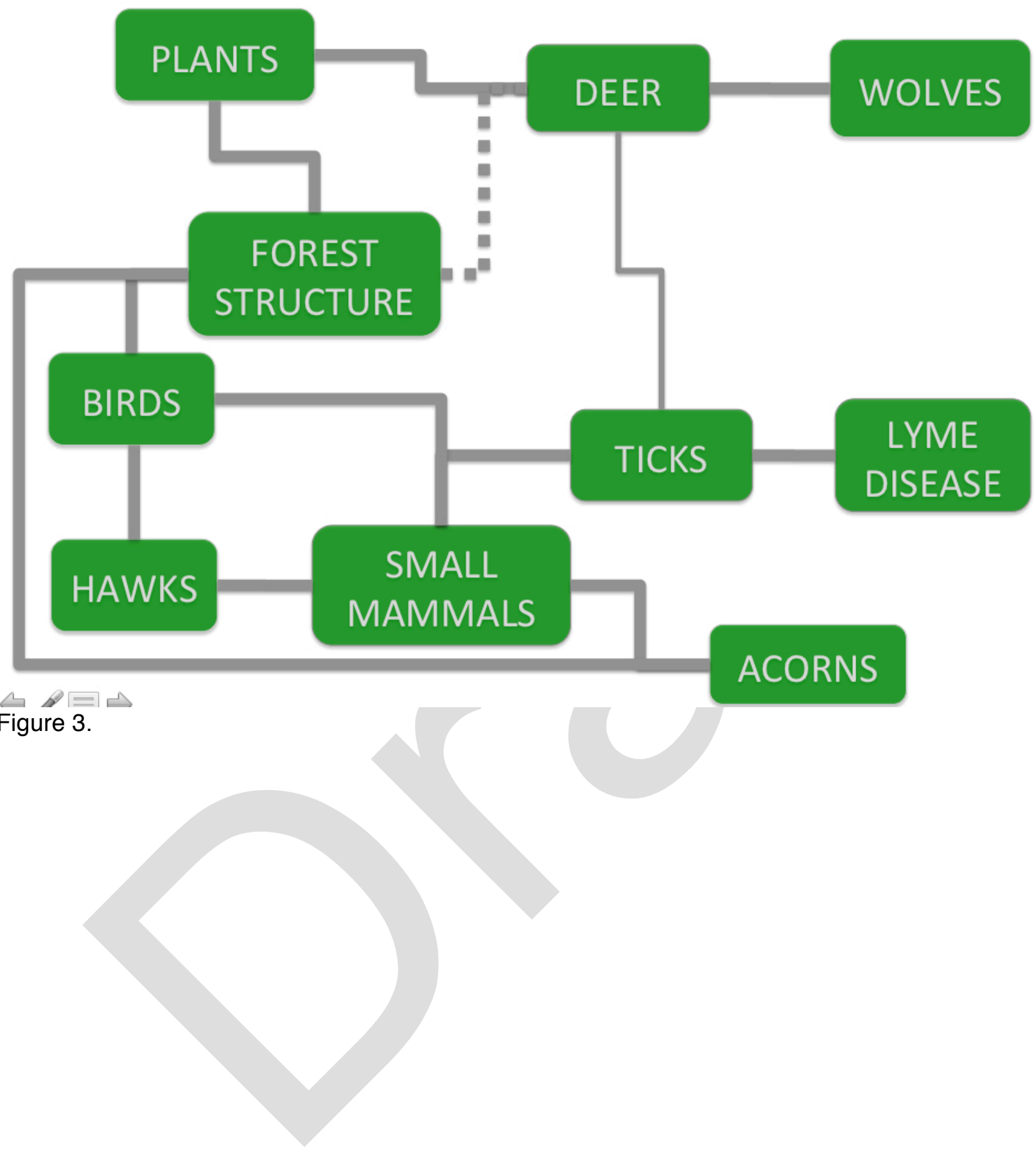




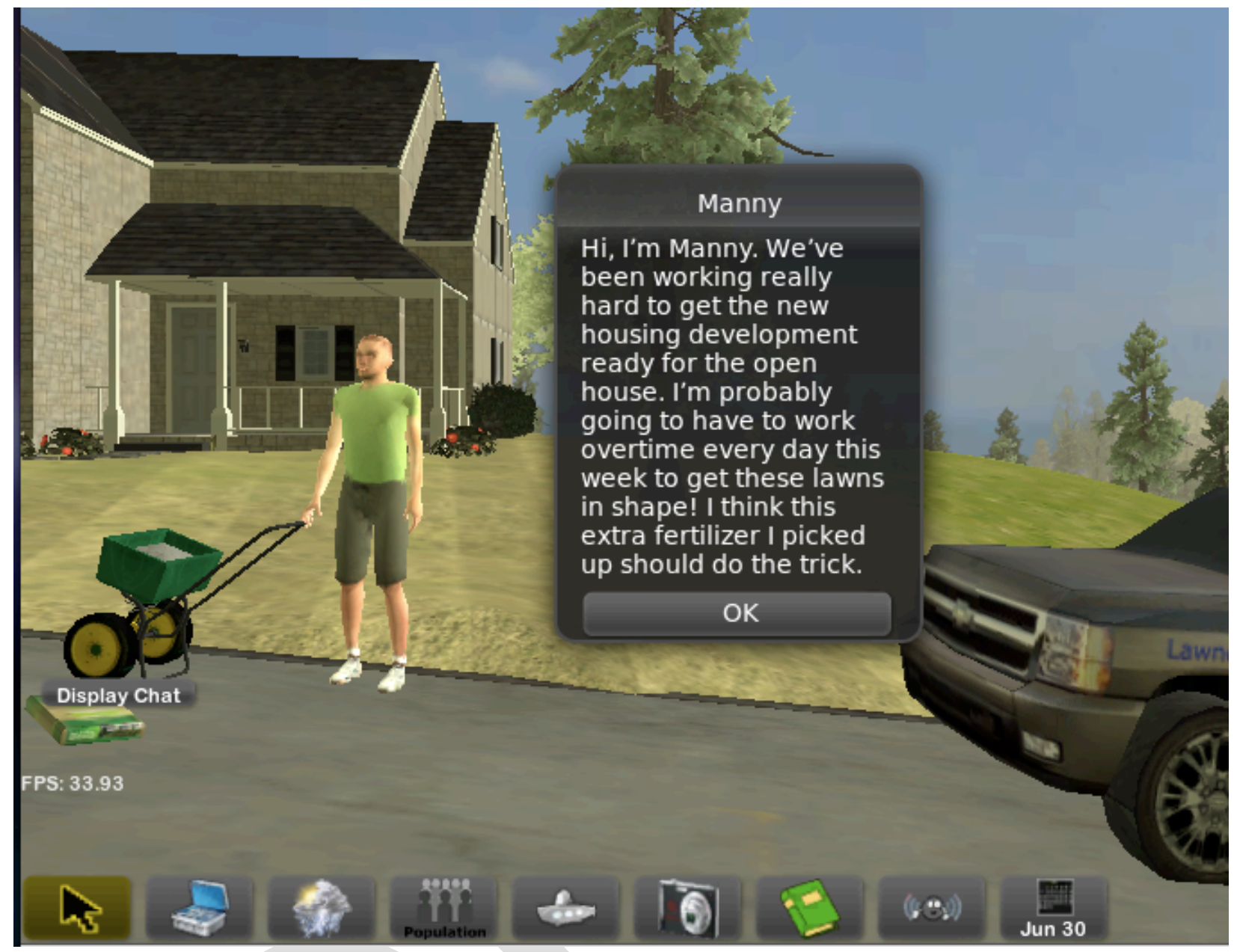

Figure 4.

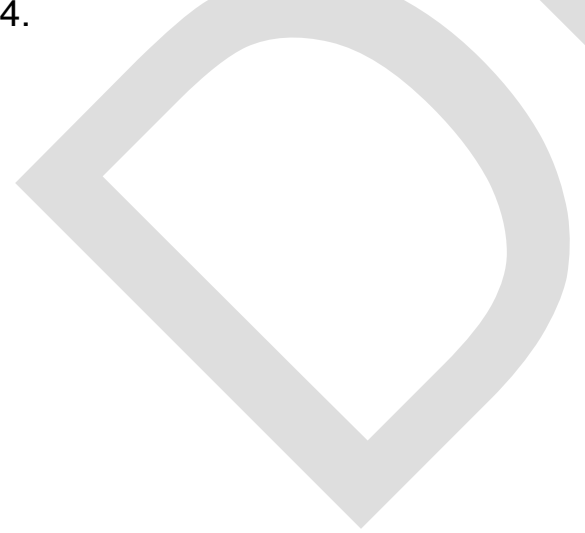




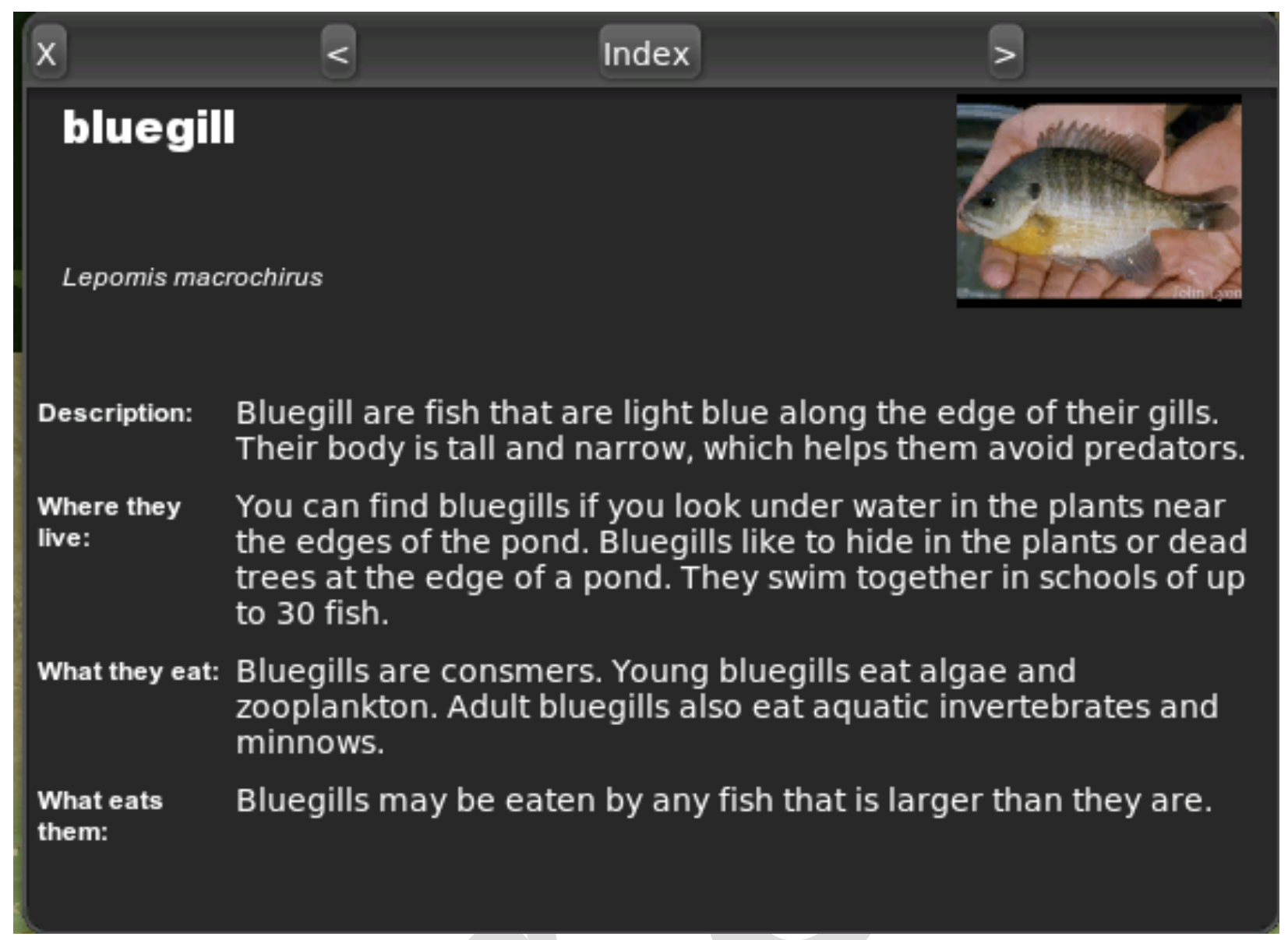

Figure 5.

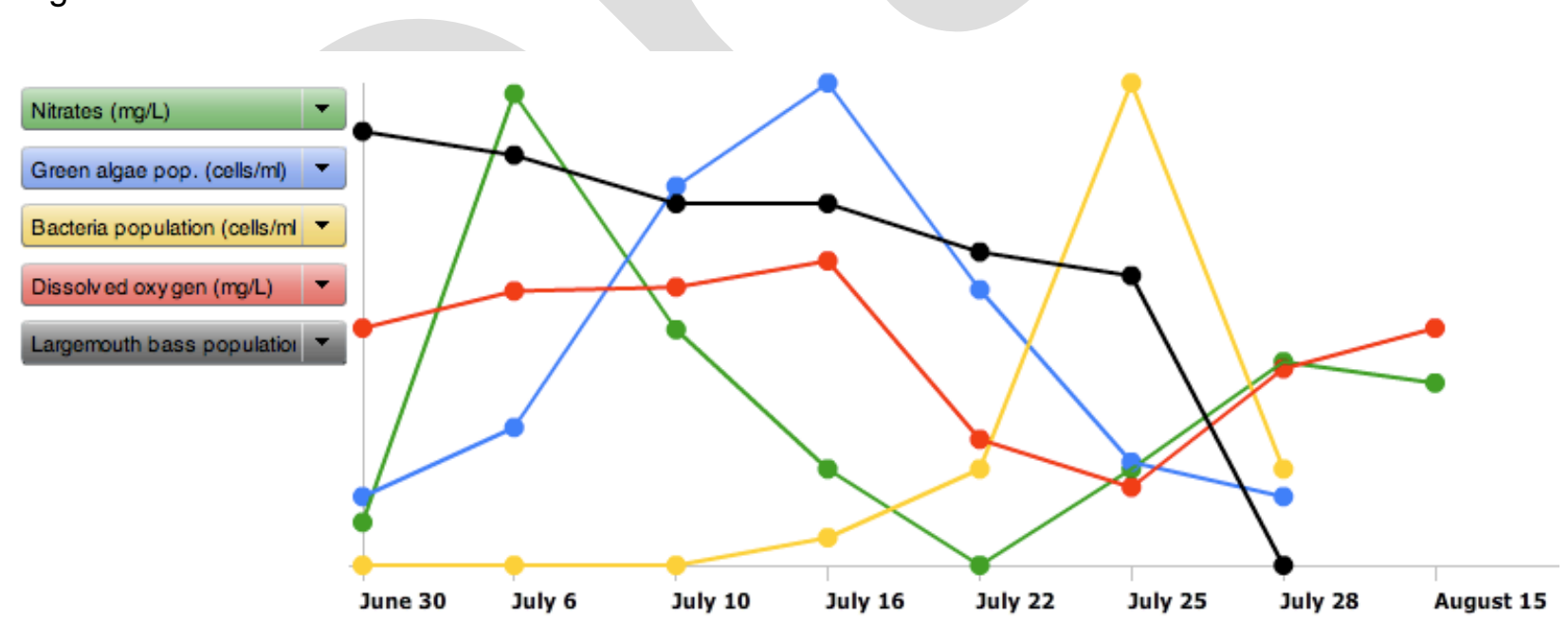

Figure 6. 


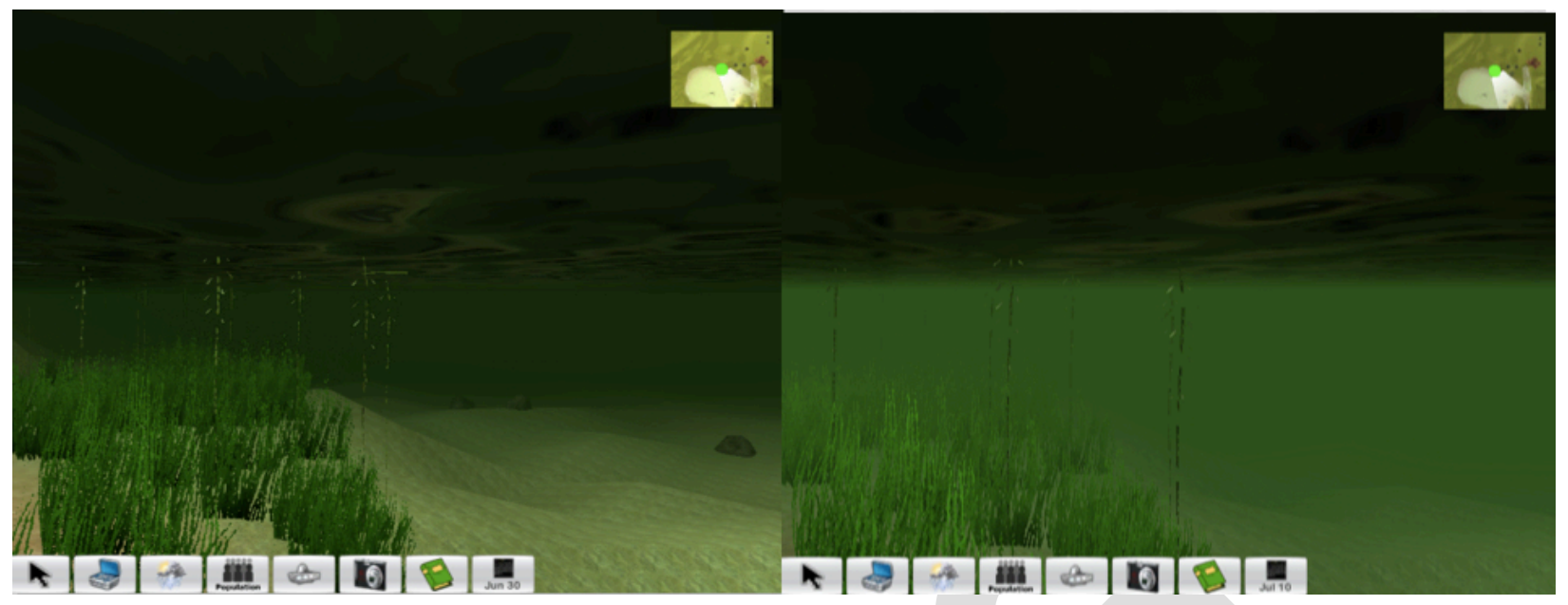

Figure 7.

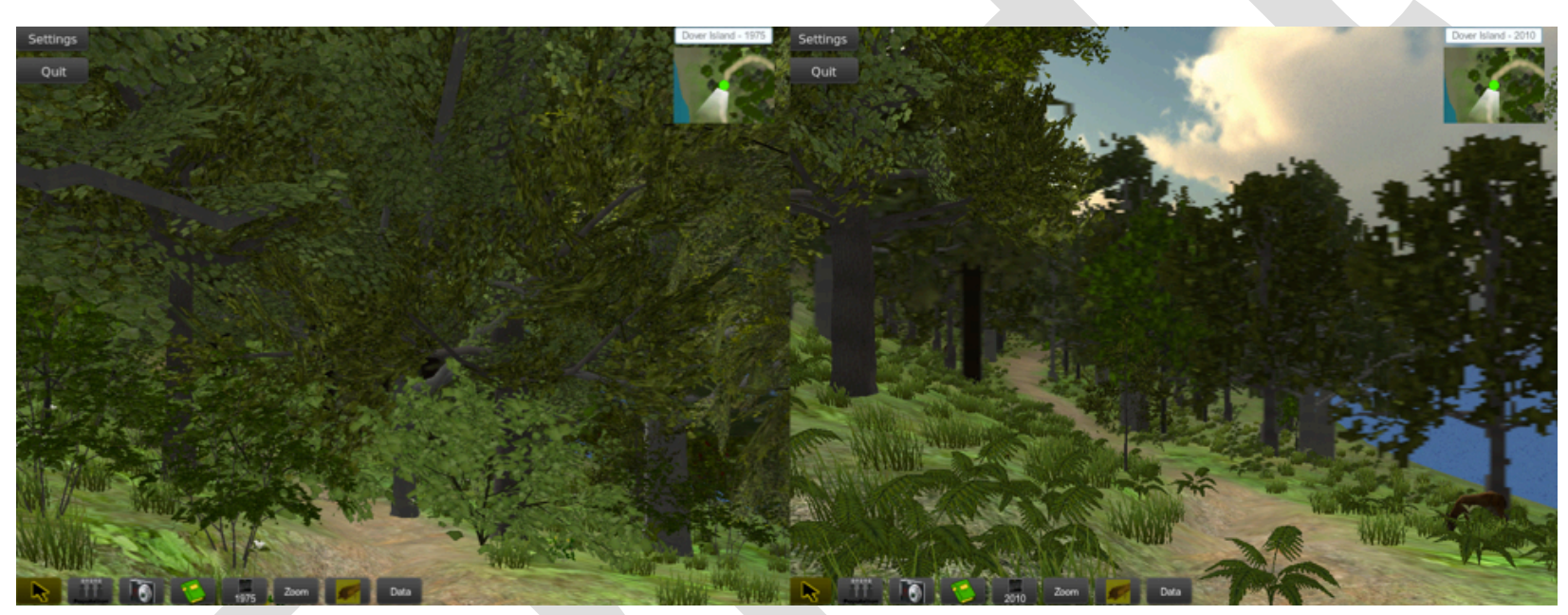

Figure 8. 